\title{
Detection of Hot Spot in a Neutral Joint of Power Transformer Using Infrared Technology
}

\author{
Rabi Pradhan* and Yeshi Lham** \\ * Thermographer Level-I, CoEVaTA, Druk Green, Bhutan, ravicoevata@gmail.com \\ ** Section Officer, CoEVaTA, Druk Green, Bhutan, yeshilham12@gmail.com
}

\begin{abstract}
Tala Hydropower Plant (THP) under Druk Green consists of six identical generating units rated at $170 \mathrm{MW}$ each. The power is evacuated from 18 numbers of single phase transformers rated at $70 \mathrm{MVA}, 13.8 \mathrm{kV} / 400 \mathrm{kV}$. Condition monitoring of electrical systems in all the Druk Green hydropower plants are enhanced by Flir P660 infrared thermography camera.

Thermal anomaly in an electrical system is best detected by using Infrared techniques. Generally the hot spots are detected in load carrying system but it was alarming to detect hot spot on non-load carrying system too. Such observation has been made in only one neutral joint of a power transformer at THP.

Several hot spots at similar point of other transformers were detected and rectified. In this paper the reappearance of one hot spot is discussed including rectification activities, temperature trend and recommendations. The thermal anomaly is periodically monitored and timely rectified.
\end{abstract}

